\title{
COVID-Q: validation of the first COVID-19 questionnaire based on patient-rated symptom gravity
}

\author{
Giacomo Spinato $^{1}$, Cristoforo Fabbris ${ }^{1}$, Federica Conte $^{2}$, Anna Menegaldo ${ }^{1}$, Leonardo \\ Franz $^{1}$, Piergiorgio Gaudioso ${ }^{1}$, Francesco Cinetto ${ }^{3}$, Carlo Agostini ${ }^{3}$, Giulio Costantini ${ }^{2}$, and \\ Paolo Boscolo-Rizzo ${ }^{4}$ \\ ${ }^{1}$ Università degli Studi di Padova Dipartimento di Neuroscienze \\ ${ }^{2}$ Università degli Studi di Milano-Bicocca \\ ${ }^{3}$ Università degli Studi di Padova \\ ${ }^{4}$ Azienda Sanitaria Universitaria Integrata di Trieste
}

May 19, 2021

\begin{abstract}
Objectives The aim of the present study is to develop and validate the COVID-Q, a novel symptom questionnaire specific for COVID-19 patients, to provide a comprehensive and standard clinical evaluation. A secondary goal of the present study was to evaluate the performance of the COVID-Q in identifying subjects at higher risk of being tested positive for COVID-19. Material and methods 460 subjects (230 COVID-19 cases and 230 healthy controls), answered the COVID-Q. Parallel Analysis and Principal Component Analysis were used to identify clusters of items measuring the same dimension. The IRT-based analyses evaluated the functioning of item categories, the presence of clusters of local dependence among items, item fit within the model and model fit to the data. Results Parallel analysis suggested the extraction of six components, which corresponded to as many clinical presentation patterns: asthenia, influenza-like symptoms, ear and nose symptoms, breathing issues, throat symptoms, and anosmia/ageusia. The final IRT models retained 27 items as significant for symptom assessment. The total score on the questionnaire was significantly associated with positivity to the molecular SARS-CoV-2 test. Subjects with multiple symptoms were significantly more likely to be affected by COVID-19 $(\mathrm{p}<.001)$. Older age and male gender also represented risk factors. None of the examined comorbidities had a significant association with COVID-19 diagnosis. Conclusion The application of the novel COVID-Q to everyday clinical practice may help identifying subjects who are likely to be affected by COVID-19 and address them to a nasopharyngeal swab in order to achieve an early diagnosis.
\end{abstract}

\section{Hosted file}

COVID-Q_-_Manuscript_16-05-21.docx available at https://authorea.com/users/414638/articles/ 522631-covid-q-validation-of-the-first-covid-19-questionnaire-based-on-patient-ratedsymptom-gravity 


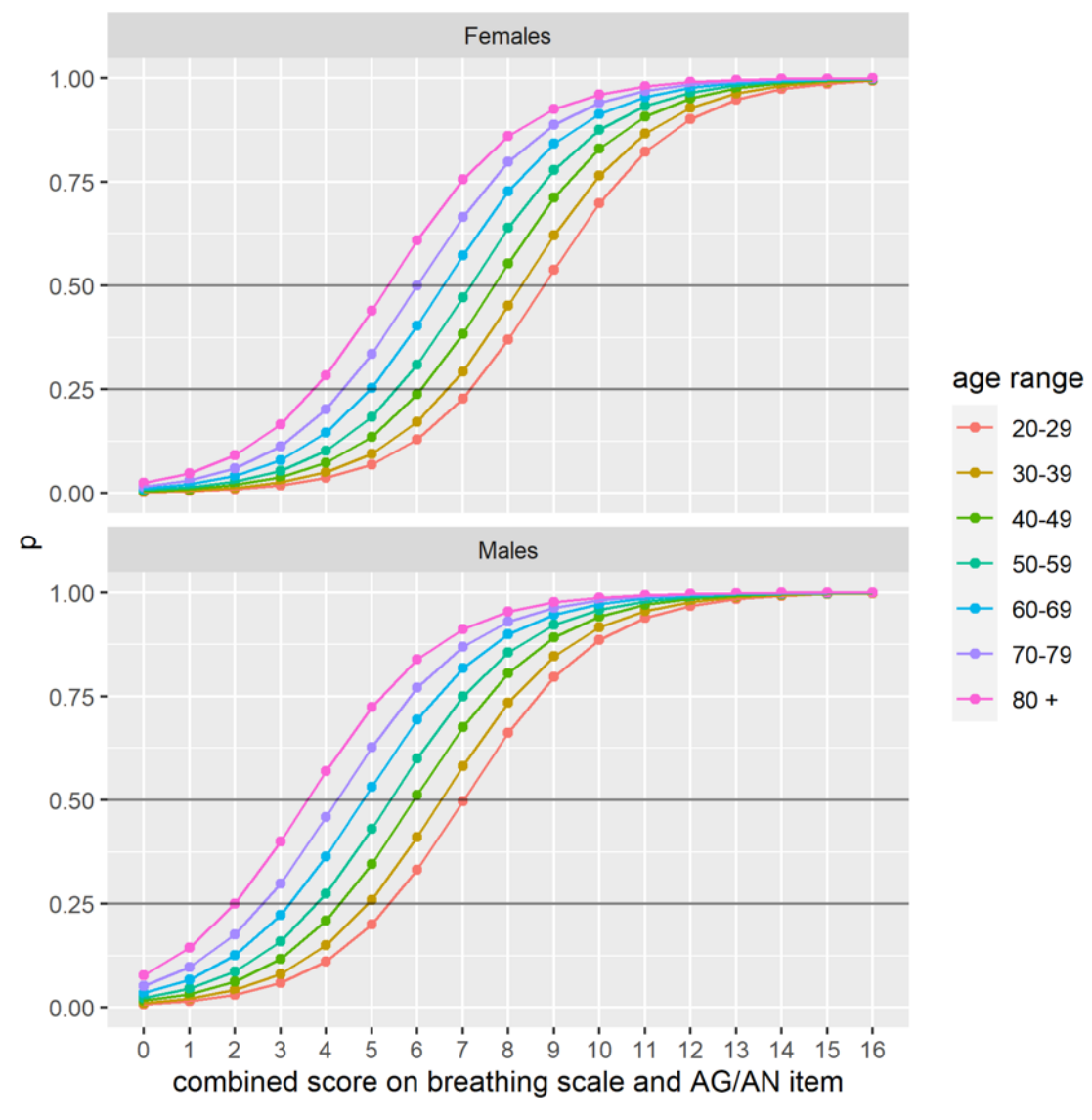

\section{Hosted file}

COVID-Q - Tables 16-05-21.docx available at https://authorea.com/users/414638/articles/ 522631-covid-q-validation-of-the-first-covid-19-questionnaire-based-on-patient-ratedsymptom-gravity 